\title{
TOOL WEAR AND SURFACE FINISH INVESTIGATION OF HARD TURNING USING TOOL IMAGING
}

\author{
A. V. N. L. Sharma ${ }^{1}$, K. V. G. Rama Seshu ${ }^{2}$, A. Gopichand ${ }^{3}$, K. V. Subbaiah ${ }^{4}$ \\ avnls277522@gmail.com, karriseshu@gmail.com,allkagopichand@gmail.com
}

\begin{abstract}
Surface roughness and tool wear is one of the most specified customer requirements in a machining process. To predict the surface roughness and tool wear, Genetic Algorithm\& Image processing model was designed through MATLAB 7.1 software for the data obtained.
\end{abstract}

Keywords: Tool wear, Profile projector, GA.

\section{INTRODUCTION}

The technology of metal cutting is a permanent evolution and is a field of much interest in terms of computer applications. Cutting tool wear detection is a fundamental aspect in the evolution of production techniques. As the quality of the cutting tool is directly related to the quality of the product, the level of tool wear should be kept under control during machining operations. The recognition of the general conditions of a cutting tool has a major role in the optimization of machining processes, since the accurate prediction of the exact moment for tool change results in many cases in an effective economy: a longer cutting tool life can be achieved, tolerances can be under control and rejection of pieces by deterioration of the tool conditions can be prevented.

In metal cutting, tool wear on the tool-chip and tool-work piece interfaces (i.e. flank wear and crater wear) is strongly influenced by the cutting temperature, contact stresses, and relative sliding velocity at the interface. These process variables depend on tool and work piece materials, tool geometry and coatings, cutting conditions, and use of coolant for the given application.

In this study, profile projector and digital image processing methods are used for measurement of the tool geometry and tool wear.

\subsection{EXPERIMENTAL PROCEDURE}

Experimental details and specifications

Machine tool: $\quad$ Lathe machine

Work material: $\quad$ EN8 steel

Cutting tool: High speed steel
1.2Process parameters and their levels:

\begin{tabular}{|l|l|l|l|}
\hline Level & $\begin{array}{l}\text { Speed }(\mathbf{v}) \\
(\mathbf{r p m})\end{array}$ & $\begin{array}{l}\text { Feed rate(f) } \\
(\mathbf{m m} / \mathbf{r e v})\end{array}$ & $\begin{array}{l}\text { Depth of cut(d) } \\
(\mathbf{m m})\end{array}$ \\
\hline 1 & 228 & 0.06 & 0.4 \\
\hline 2 & 450 & 0.08 & 0.6 \\
\hline
\end{tabular}

1.3Available Cutting Parameters \& Ranges

\begin{tabular}{|l|l|}
\hline Speed, V (rpm) & $228,250,360,450,580,740$ \\
\hline Feed rate, f $(\mathrm{mm} / \mathrm{rev})$ & $0.05,0.06,0.07,0.08,0.1$ \\
\hline Depth of cut, d (mm) & $0.4,0.5,0.6,0.7,0.9,1$ \\
& \\
\hline
\end{tabular}

2. SPECIFICATION FOR THE WORK PIECE MATERIAL

Size of the material is $\quad: \varnothing 34 \times 1500 \mathrm{~mm}$

2.1 Chemical composition for the EN8 steel:

\begin{tabular}{|c|c|c|c|c|}
\hline C. & Si. & Mn. & S. & P. \\
\hline $0.40 \%$ & $0.25 \%$ & $0.80 \%$ & $0.015 \%$ & $0.015 \%$ \\
\hline
\end{tabular}




\subsection{IMAGE Tool Overview}

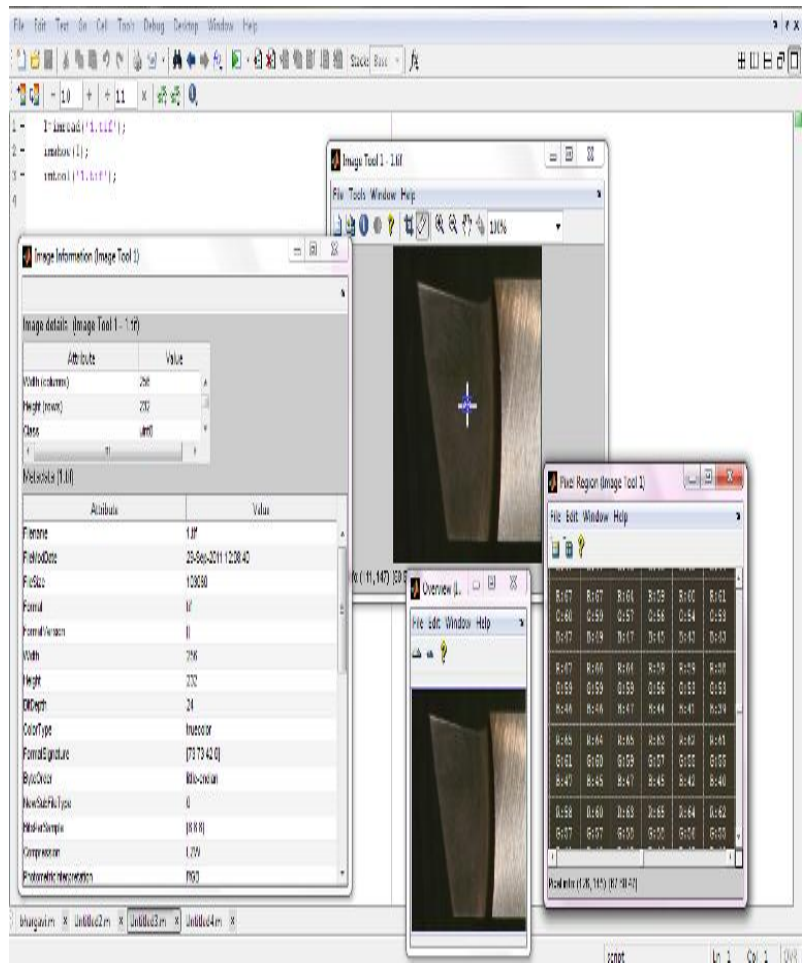

\subsection{Displaying result}
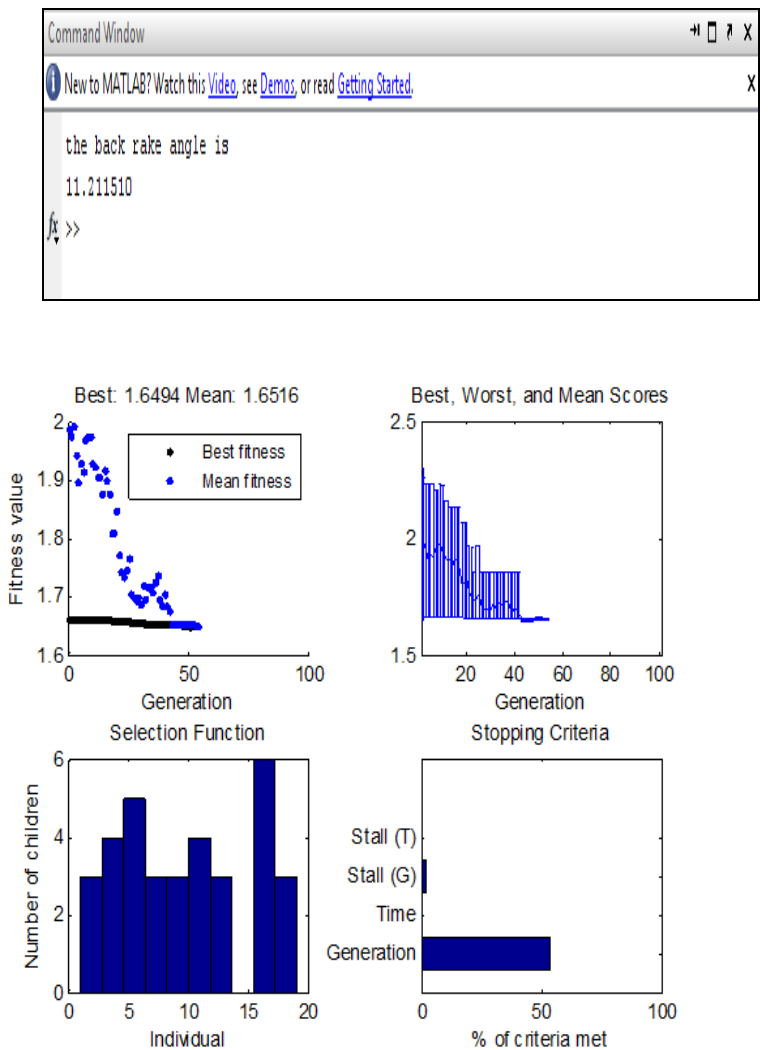

Different graphs of GA Output function

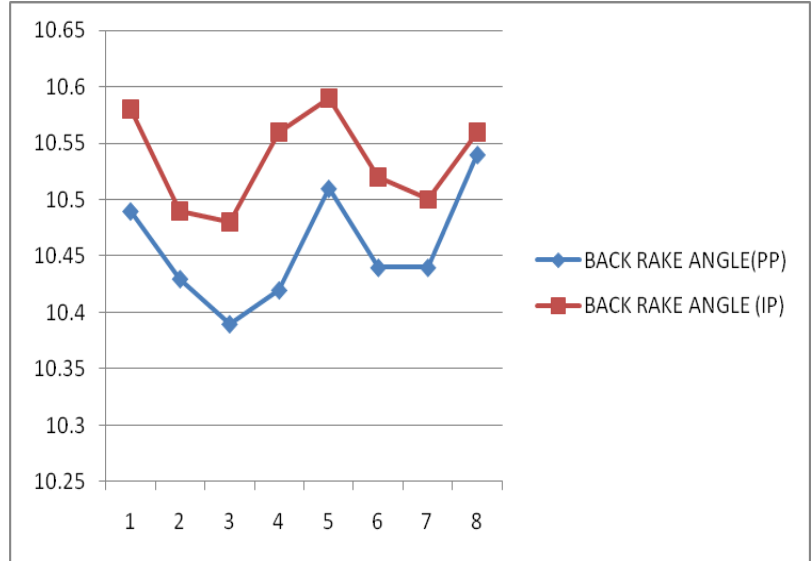

Graph-a Comparision of Back rake angle values of HSS tool

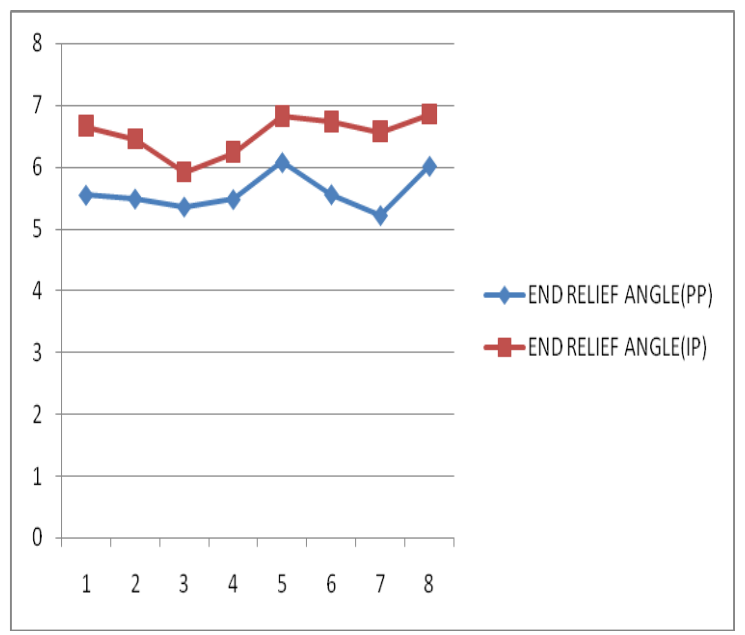

Graph .bComparision of End relief angle values of HSS tool

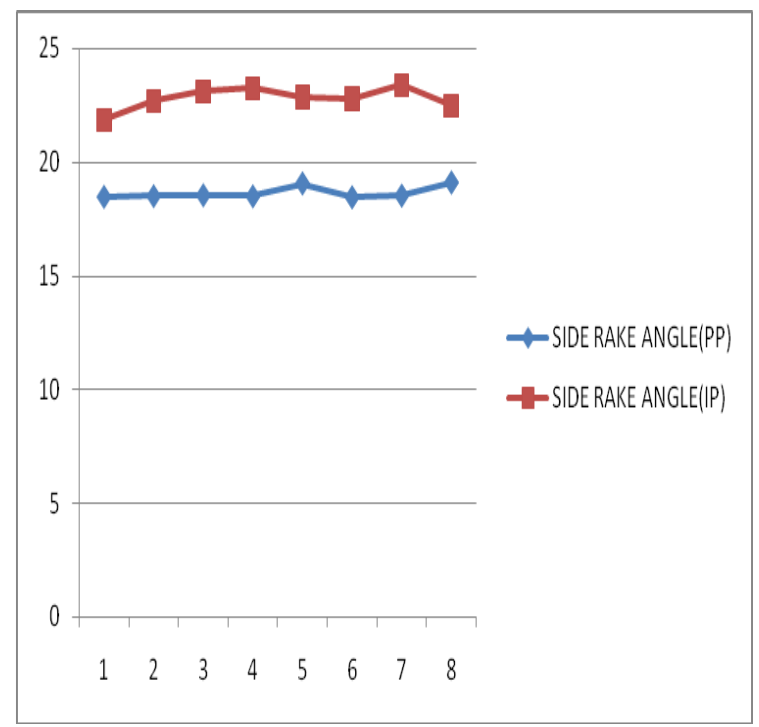

Graph .C Ccmparision of Side rake angle values of HSS tool 


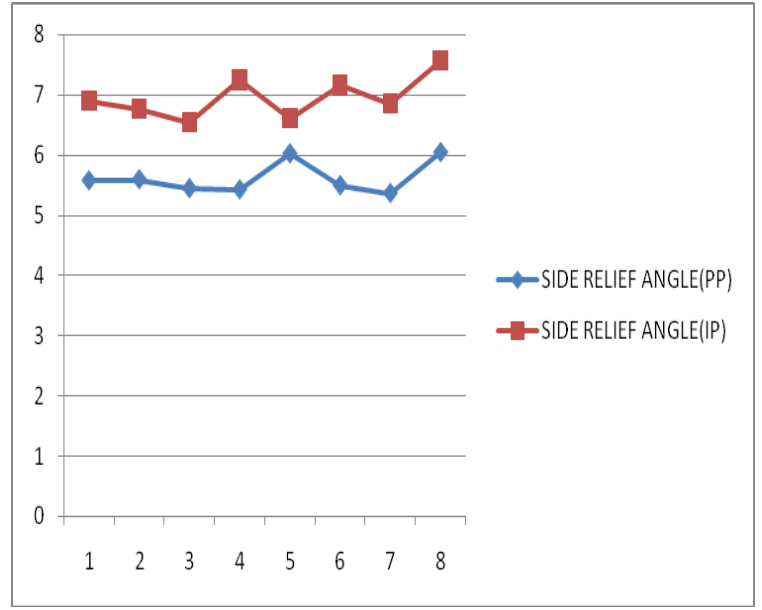

Graph -Comparision of Side relief angle values of HSS tool

\subsection{Finding tool wear area through image analysis}

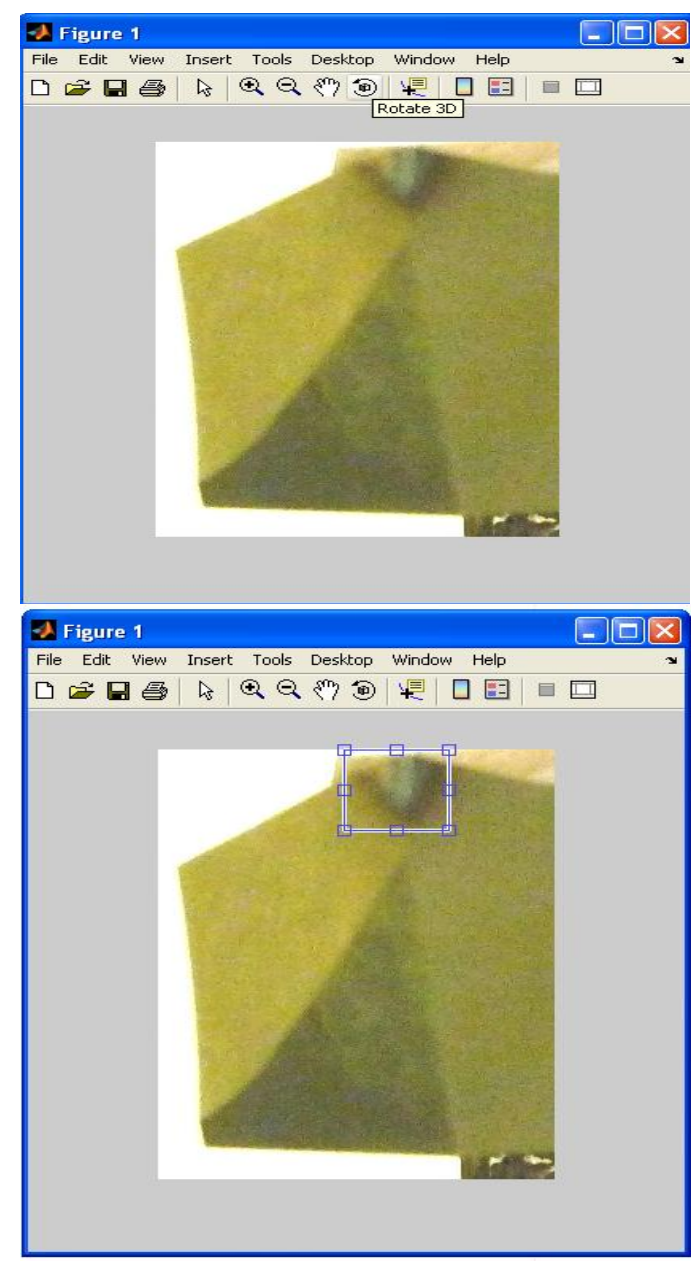

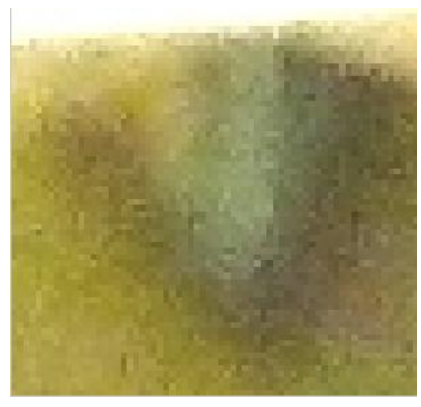

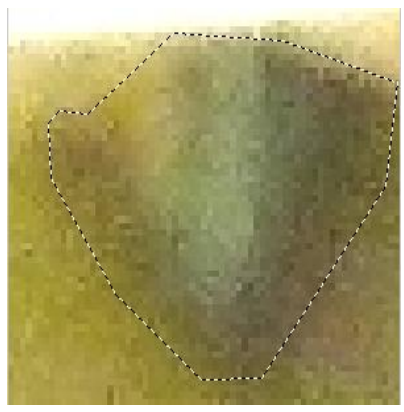

Figure.a Images for finding wear area of the first HSS tool

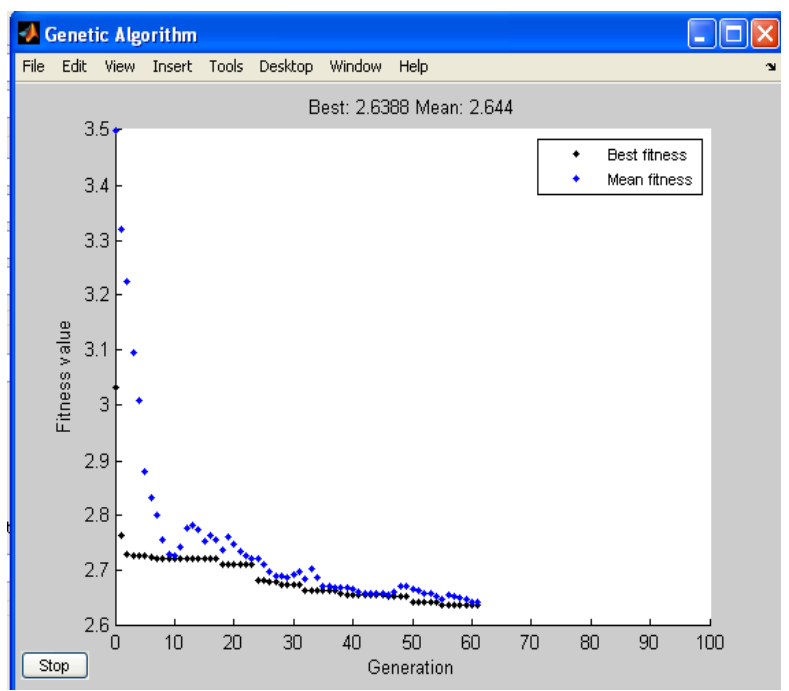

Fitness value vs. Generation

\section{RESULTS \& CONCLUSION:}

The contact phenomena on the tool flank surface are of interest because understanding them allows the explanation of tool flank wear and the formation of surface integrity of machined surfaces on work pieces. Flank wear of cutting tools is often selected as tool life criterion because it determines the dimensional accuracy of machining, its stability and reliability. An attempt is made to determine the flank wear from image processing method for EN8 material with HSS tool and the following conclusions has been drawn.

A new technique is implemented in determining flank wear area i.e image processing. The deviation of results between the two methods is explained below:

$>$ At speed $=450 \mathrm{rpm}$, feed $=0.08 \mathrm{~mm} / \mathrm{rev}$ and depth of cut $=0.6$ maximum tool wear area is obtained by image processing. The deviation with conventional method is $15.328 \%$.

$>$ At speed $=450 \mathrm{rpm}$, feed $=0.06 \mathrm{~mm} / \mathrm{rev}$ and depth of cut $=0.6$ minimum tool wear area is obtained by image processing. The deviation with conventional method is $17.526 \%$. 


\section{REFERENCES:}

[1] Adeel H. Suhail, N. Ismail, S.V. Wong and N.A. Abdul Jalil [2010], Optimization of Cutting Parameters Based on Surface Roughness and Assistance of Workpiece Surface Temperature in Turning Process, American J. of Engineering and Applied Sciences 3 (1): 102-108, 2010

[2] Adesta Erry Yulian T., Riza Muhammad, Hazza Muataz, Agusman Delvis, Rosehan, Tool Wear and Surface Finish Investigation in High Speed Turning Using Cermet Insert by Applying Negative Rake Angles, European Journal of Scientific Research Vol.38 No.2 (2009): pp.188.

[3] Ali, S.M. and Dhar, N.R., 2010, "Tool Wear and Surface Roughness Prediction using an artificial Neural Network in Turning Steel under Minimum Quantity Lubrication", International Conference on Industrial EngineeringICIE-2010, WASET Conference Proceedings, 62(4), 607-616.

[4] Aslan E, Camuşcu N, Bingören B (2007). Design optimization of cutting parameters when turning hardened AISI 4140 (63 HRC) with Al2O3+TiCN mixed ceramic tool, Mater. Design, 28: 1618-1622.

[5] A. Kohli · U.S. Dixit [2005], "A neural-network-based methodology for the prediction of surface roughness in a turning process" Int J Adv Manuf Technol (2005) 25: 118-129 Ishibuchi H, Tanaka H (1991) Regression analysis with interval model by neural networks. Proc of the IEEE Int Joint Conf on Neural Networks, Singapore, pp 1594-1599.

[6] Abburi NR, Dixit US (2006). A knowledge-based system for the prediction of surface roughness in turning process. Robotics and Comp.-Integ. Manu., 22: 363-372.

[7] Asilturk I, Cunkas M (2011). Modelling and prediction of surface roughness in turning operations using artificial neural network and multiple regression method. Expert Sys. Appl., 38(5): 5826-5832. 